\title{
Kompetenensi dan Kinerja Auditor: Peran Moderasi Struktur Audit dan Supervisi Audit
}

\author{
Ni Made Leny Pebriyaningrum ${ }^{1}$ \\ Fakultas Ekonomi dan Bisnis \\ Universitas Udayana, Indonesia
}

\author{
A.A.N.B. Dwirandra² \\ Fakultas Ekonomi dan Bisnis \\ Universitas Udayana, Indonesia
}

Surel : lenypebriyaningrum@gmail.com

\section{ABSTRAK}

Tujuan penelitian ini adalah untuk mengetahui moderasi struktur audit dan supervisi audit pada pengaruh kompetensi pada kinerja auditor. Lokasi penelitian ini dilakukan pada Kantor Akuntan Publik (KAP) Provinsi Bali. Data penelitian ini menggunakan data primer yang diolah melalui penyebaran kuisioner dengan teknik analisis data menggunakan analisis regresi moderasi. Hasil penelitian ini menunjukkan bahwa kompetensi berpengaruh positif terhadap kinerja auditor. Hasil penelitian menunjukkan bahwa struktur audit menguatkan pengaruh positif kompetensi pada kinerja auditor di Kantor Akuntan Publik. Hasil penelitian juga menunjukkan bahwa Supervisi audit menguatkan pengaruh positif kompetensi pada kinerja auditor di Kantor Akuntan Publik.

Kata Kunci: Struktur Audit; Supervisi Audit; Kompetensi; Kinerja Auditor.

\section{Auditor Competence and Performance: The Role of Audit Structure Moderation and Audit Supervision}

\section{ABSTRACT}

The purpose of this study was to determine the moderation of the audit structure and audit supervision on the effect of competence on auditor performance. The location of this research was conducted at the Public Accounting Firm (KAP) of the Province of Bali. This research data uses primary data that is processed through the distribution of questionnaires with data analysis techniques using moderation regression analysis. The results of this study indicate that competence has a positive effect on auditor performance. The results showed that the audit structure strengthened the positive effect of competence on auditor performance in the Public Accounting Firm. The results also showed that audit supervision strengthened the positive effect of competence on auditor performance in the Public Accounting Firm.

Keywords: Audit Structure; Audit Supervision; Competence; Auditor Performance.

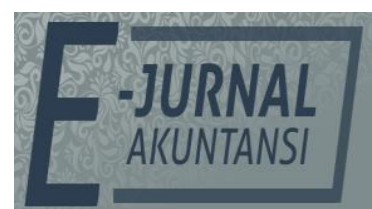

e-ISSN 2302-8556

Vol. 30 No. 11

Denpasar, Nopember 2020

Hal. 2878-2891

DOI:

10.24843/EJA.2020.v30.i11.p13

PENGUTIPAN:

Pebriyaningrum, N.M.L. \& Dwirandra, A.A.N.B. (2020).

Komptensi dan Kinerja

Auditor: Peran Moderasi Struktur Audit dan Supervisi

Audit. E-Jurnal Akuntansi, 30(11), 2878-2891

RIWAYAT ARTIKEL: Artikel Masuk: 11 Maret 2020 Artikel Diterima: 7 Juli 2020

Artikel dapat diakses : https://ojs.unud.ac.id/index.php/Akuntansi/index 


\section{PENDAHULUAN}

Saat ini persaingan di dunia usaha semakin meningkat seiring dengan berkembangnya beragam jenis industri. Berbagai cara dilakukan untuk tetap bertahan ditengah persaingan yang begitu ketat. Perusahaan tidak bisa bersaing hanya dengan memperlihatkan laba yang tinggi, tetapi kewajaran dari laporan keuangan tersebut jauh lebih penting. Upaya yang sering dilakukan perusahaan yaitu dengan melakukan pemeriksaan laporan keuangan oleh akuntan publik. Hal ini tidak lepas dari semakin banyaknya pihak-pihak yang memerlukan laporan keuangan hasil audit yang dapat dipercaya. Jasa akuntan publik yang bekerja di Kantor Akuntan Publik sangat diperlukan untuk menilai apakah laporan keuangan suatu perusahaan disajikan secara wajar dan dapat dipertanggungjawabkan (Raiyani \& Suputra, 2014).

Akuntan publik merupakan sebuah organisasi yang bergerak dalam bidang jasa. Akuntan publik mendapat kepercayaan dari klien untuk melaksanakan pemeriksaan akuntan untuk membuktikan kewajaran laporan keuangan yang disusun dan disajikan oleh klien. Klien mempunyai kepentingan yang berbeda, bahkan mungkin bertentangan dengan kepentingan para pemakai laporan keuangan. Demikian pula, kepentingan pemakai laporan keuangan yang satu berbeda dengan pemakai laporan keuangan yang lainnya. Al-khaddash et al., (2013) menyatakan bahwa untuk menunjang keberhasilan dalam menjalankan tugas dan fungsinya dengan baik, kinerja auditor yang baik dan berkualitas sangat diperlukan.

Kinerja merupakan hasil kerja yang dicapai seseorang dalam melaksanakan tugas sesuai dengan tanggung jawab yang diberikan (Kalbers, \& Fogarty, 1995). Menurut Dali \& Mas'ud (2014) kinerja auditor adalah kemampuan seorang auditor dalam menghasilkan temuan dari tugasnya dalam kegiatan pemeriksaan. Kinerja auditor merupakan suatu hasil kerja yang dicapai seseorang auditor yang melakukan pekerjaannya dalam pemeriksaan laporan keuangan, dan menjadi suatu pengukuran apakah hasil kerja seseorang auditor tersebut sudah baik ataupun buruk (Elizabeth \& Friska, 2013). Auditor diharapkan mampu melaksanakan tugas dengan baik dalam waktu yang sudah ditentukan. Hal ini ditunjukan untuk menjamin bahwa pelaksanaan kegiatan tersebut telah sesuai dengan kebijakan rencana yang telah disepakati sebelumnya agar dalam pencapaian tersebut sesuai dengan keinginan dan kebutuhan terhadap kebijakan peraturan dan hukum yang berlaku (Azza \& Zhou, 2011).

Kasus kegagalan audit dalam beberapa dekade belakangan ini telah menimbulkan krisis kepercayaan masyarakat mengenai kemampuan profesi akuntan dalam mengaudit laporan keuangan. Munculnya krisis ini beralasan karena cukup banyak laporan keuangan suatu perusahaan yang mendapat opini wajar tanpa pengecualian, tetapi justru menghadapi masalah dalam kelangsungan usahanya setelah opini tersebut dikeluarkan (Fitriani \& Daljono, 2012). Beberapa kasus kegagalan audit banyak terjadi di dunia, dimulai dari kasus besar Enron pada tahun 2001 yang juga melibatkan Kantor Akuntan Publik (KAP) besar Arthur Enderson dalam upaya memanipulasi laba perusahaan. Kasus yang terjadi di Indonesia yaitu kasus Bank Lippo tahun 2002, dimana KAP Prasetyo, Sarwoko \& Sandjaja dengan auditor eksternal Ruchjat Kosasih mencantumkan kata "diaudit" dan "opini wajar tanpa pengeculaian" di laporan 
keuangan untuk publik dan diiklankan di media massa padahal laporan keuangan tersebut belum diaudit dan terlambat menyampaikan informasi penting mengenai penurunan agunan yang diambil alih Bank Lippo selama 35 hari (Santoso, 2012).

Kasus gagal audit berpotensi merugikan profesi audit seperti menurunnya profesionalisme, hilangnya kepercayaan publik dan kredibilitas sosial, serta reputasi akuntan publik (Hartanto, 2001). Atas kasus tersebut maka dibutuhkan kinerja auditor yang baik dalam hal penugasan auditor junior harus disupervisi secara memadai dan menggunakan struktur audit yang lebih efisien (Coram et al., 2003). Karena seorang auditor harus mampu mengungkapkan, mendeteksi, dan menciptakan laporan audit secara seksma agar dapat mendeteksi kecurangan-kecurangan yang terjadi di dalam perusahaan.

Terdapat tiga faktor yang memengaruhi kinerja auditor yaitu faktor individu, tugas, dan lingkungan (Bonner \& Sprinkle, 2002). Faktor individu meliputi karakteristik individu auditor yang melaksanakan tugas seperti motivasi, kepribadian, kepercayaan diri, pengetahuan, dan kemampuan auditor. Faktor tugas atau pekerjaan profesi, seperti: kompleksitas dan struktur tugas, sedangkan faktor lingkungan mencakup semua kondisi, keadaan, dan pengaruh sekitar auditor yang melakukan tugas tertentu, seperti tekanan waktu, akuntabilitas, tujuan penugasan, dan umpan balik. Selanjutnya, Pamilih (2014) mengemukakan bahwa keberhasilan maupun kinerja seseorang dalam pekerjaannya dapat ditentukan dari beberapa hal, yaitu tingkat kompetensi, profesionalisme dan juga komitmen terhadap bidang pekerjaan yang ditekuninya.

Kompetensi dapat digunakan untuk memprediksi kinerja yaitu siapa yang bekerja baik dan kurang baik tergantung kompetensi yang dimilikinya, diukur dari kriteria atau standar yang digunakan (Linawati \& Suhaji, 2012). Kompetensi merupakan suatu keahlian yang cukup secara eksplisit dapat digunakan untuk melakukan audit secara objektif (Lee \& Stone, 1995). Kompetensi diatur dalam Standar Umum yang ketiga menyatakan bahwa dalam pelaksanaan audit dan penyusunan laporannya, auditor wajib menggunakan kemahiran profesionalnya dengan cermat dan seksama (Standar Audit seksi 230 dalam SPAP, 2001). Oleh karena itu, setiap auditor wajib memiliki kemahiran profesionalitas dan keahlian dalam melaksanakan tugasnya sebagai auditor. Penelitian tentang pengaruh kompetensi pada kinerja auditor telah dilakukan beberapa peneliti dan ternyata menemukan hasil berbeda. Sujana (2012), Ariani (2015), Nurnaluri \& Cahyaniza (2017) dan Suharni (2017) dalam penelitiannya menemukan bahwa kompetensi berpengaruh positif dan signifikan terhadap kinerja auditor. Sedangkan, penelitian yang dilakukan oleh Linawati \& Suhaji (2012), Sholihah (2018) dan Siagian \& Karo, (2018) mengungkapkan bahwa kompetensi tidak berpengaruh signifikan terhadap kinerja auditor.

Ketidakkonsistenan hasil-hasil penelitian sebelumnya patut diduga disebabkan karena adanya peranan faktor atau variabel lain. Hal ini memotivasi peneliti untuk melakukan penelitian dengan menggunakan struktur audit dan supervisi audit sebagai variabel moderasi. Seperti yang dikatakan oleh Govindarajan (1986) menyatakan bahwa kemungkinan belum adanya kesatuan hasil penelitian tergantung faktor-faktor tertentu atau lebih dikenal dengan 
istilah faktor kontingensi. Murray (1990) menjelaskan bahwa agar dapat merekonsiliasi hasil yang saling bertentangan diperlukan pendekatan kontingensi untuk mengidentifikasi variabel lain yang bertindak sebagai pemoderasi ataupun pemediasi dalam model riset. Variabel penelitian yang diduga kuat mampu memoderasi pengaruh kompetensi pada kinerja auditor tidak bisa dilepaskan dari teori atribusi. Menurut teori Atribusi, motivasi seseorang didasari oleh faktor eksternal dan internal (Namora, 2011: 88).

Faktor eksternal yaitu lingkungan kerja yang berkontribusi pada kinerja auditor salah satunya adalah struktur audit yaitu suatu pendekatan sistematis terhadap audit yang dikarakteristikkan oleh langkah-langkah penentuan audit, prosedur rangkaian logis, keputusan, dokumentasi, dan menggunakan sekumpulan alat-alat dan kebijakan audit, yang komprehensif dan terintegrasi untuk membantu auditor melakukan audit (Bowrin, 1998). Hal ini berkaitan dengan koordinasi arus kerja, wewenang yang dimiliki, komunikasi dan kemampuan beradaptasi sehingga pengguna pendekatan struktur audit diharapkan dapat meningkatkan kinerja auditor menjadi lebih baik (Bamber et al., 1989).

Supervisi adalah salah satu faktor eksternal penentu perilaku seseorang yang berdampak pada kinerja yang diberikan. Supervisi adalah tindakan mengawasi atau mengarahkan penyelesaian pekerjaan (Tethool \& Rustiana, 2003). Tindakan supervisi diatur dalam Standar Pekerjaan Lapangan yang pertama menyatakan bahwa pekerjaan harus direncanakan sebaik-baiknya dan jika menggunakan asisten harus disupervisi dengan semestinya (Standar Audit seksi 150 dalam SPAP, 2001). Dengan adanya tindakan supervisi diharapkan auditor senior untuk selalu mengontrol, membimbing, mengawasi, mengevaluasi kinerja dari auditor pemula dan memberikan pelatihan audit yang cukup sehingga kompetensi dari seorang auditor pemula tersebut dapat tumbuh seiring dengan pengalaman yang terus bertambah dari waktu ke waktu.

Kompetensi adalah karakteristik yang mendasari seseorang berkaitan dengan efektivitas kinerja individu dalam pekerjaannya atau karakteristik individu yang memiliki hubungan kausal atau sebagi sebab akibat dengan kriteria yang dijadikan acuan, efektif atau berkinerja prima superior ditempat kerja pada situasi tertentu (Spencer, 1993). Kompetensi merupakan variabel utama yang harus dimiliki oleh auditor dalam melaksanakan pekerjaannya sehingga dengan adanya kompetensi yang telah dimiliki dapat membantu auditor di dalam menyelesaikan pekerjaan sesuai dengan target yang telah ditentukan. Menurut penelitian Erwin et al., (2017) dan Dyana \& Yadnya (2017) yang menunjukkan bahwa kompetensi berpengaruh signifikan terhadap kinerja auditor . Hal ini juga didukung oleh Sujana (2012), Ariani (2015), Nurnaluri \& Cahyaniza (2017), Nur \& Fitri (2017) dan Nurul (2018) dalam penelitiannya menyatakan bahwa kompetensi berpengaruh positif dan signifikan terhadap kinerja auditor.

Berdasarkan paparan teoritis dan hasil riset empiris maka dapat diketahui adanya pengaruh kompetensi pada kinerja auditor. Semakin tinggi kompetensi seorang auditor maka semakin meningkat kinerja auditnya.

$\mathrm{H}_{1}$ : Kompetensi berpengaruh positif pada kinerja auditor. 
Struktur audit adalah sebuah pendekatan sistematis terhadap auditing yang dikarakteristikkan oleh langkah-langkah penentuan audit, prosedur rangkaian logis, keputusan, dokumentasi, dan menggunakan sekumpulan alatalat dan kebijakan audit yang komprehensif dan terintegrasi untuk membantu auditor melakukan audit (Bowrin, 1998). Muslim A. Djalil (2002) menjelaskan bahwa struktur audit meliputi apa yang harus dilakukan, instruksi bagaimana pekerjaan harus diselesaikan, alat untuk melakukan koordinasi, alat untuk pengawasan dan pengendalian audit dan alat penilai kualitas kerja yang dilaksanakan. Pemahaman terhadap struktur audit yang baik dapat meningkatkan kinerja auditor. Penggunaan struktur audit dapat membantu auditor dalam melaksanakan tugasnya menjadi lebih baik sehingga meningkatkan kinerja auditor.

Hasil penelitian sebelumnya mengenai pengaruh struktur audit terhadap kinerja auditor dilakukan oleh Eriani (2010), Winidiantari \& Widhiyani (2015) hasilnya menunjukkan Struktur audit berpengaruh positif pada kinerja auditor. Selain itu penelitian yang dilakukan Sandy \& Dhini (2015), Sitorus \& Wijaya (2016) dan Aiman (2017) mengenai pengaruh struktur audit terhadap kinerja auditor, hasilnya struktur audit mempunyai pengaruh positif atau signifikan terhadap kinerja auditor.

Berdasarkan paparan teoritis dan hasil riset empiris menunjukkan bahwa struktur audit berpengaruh semakin tinggi terhadap kinerja auditor. Bila seorang auditor proses auditnya ditopang dengan stuktur audit memadai maka ia akan mampu menguatkan kompetensi untuk mencapai kinerja audit yang lebih baik.

$\mathrm{H}_{2}$ : Struktur audit menguatkan pengaruh positif kompetensi pada kinerja auditor.

Supervisi dalam auditing adalah kegiatan mengkoordinasi oleh atasan terhadap pekerjaan yang dilakukan oleh bawahannya dalam pelaksanaan tugas melalui pengarahan dan umpan balik yang efektif dan efisien, sehingga dapat mencapai suatu tujuan dan sasaran audit yang diharapkan sebelumnya (Laksmi, 2010). Salah satu bentuk dari supervisi adalah mentoring (pelatihan) yang didefinisikan sebagai proses membentuk dan mempertahankan hubungan yang berkembang, berlangsung secara intensif dari karyawan senior (pementor) dan karyawan (Chandara, 2006). Supervisor yang efektif dapat membantu menciptakan lingkungan kerja yang dapat menimbulkan tingkat kepuasan kerja yang tinggi bagi para auditor. Hasil penelitian Laksmi (2010) yang menyatakan bahwa supervisi berpengaruh signifikan pada kinerja auditor. Hasil penelitian Indriani (2014) dan Prabhawa et al., (2014) menyatakan bahwa tindakan supervisi berpengaruh positif dan signifikan pada kinerja auditor.

Berdasarkan paparan teoritis dan hasil riset terdahulu dapat diketahui bahwa supervisi berpengaruh semakin tinggi pada kinerja auditor. Bila seorang auditor disupervisi oleh supervisor atau manajer akan dapat memotivasi dirinya untuk menguatkan kompetensi guna mencapai kinerja audit maksimal.

$\mathrm{H}_{3}$ : Supervisi audit menguatkan pengaruh positif kompetensi pada kinerja auditor. 


\section{METODE PENELITIAN}

Penelitian ini dilakukan pada Kantor Akuntan Publik (KAP) di Bali yang terdaftar dalam direktori Institut Akuntan Publik Indonesia (IAPI) tahun 2019. Objek pada penelitian ini adalah kinerja auditor pada Kantor Akuntan Publik di Bali yang terdaftar dalam direktori Institut Akuntan Publik Indonesia (IAPI) tahun 2019.

Populasi dalam penelitian ini adalah seluruh auditor yang bekerja pada KAP di Bali yang terdaftar dalam Direktori Institut Akuntan Publik Indonesia (IAPI) tahun 2019 yang berjumlah 109 Auditor. Metode yang digunakan peneliti dalam pemilihan sampel penelitian adalah purposive sampling dengan teknik berdasarkan pertimbangan (judgement sampling) yang merupakan pemilihan sampel secara acak tidak acak yang informasinya diperoleh dengan menggunakan pertimbangan tertentu.

Penelitian ini melakukan uji interaksi untuk menguji variable moderating yang berupa kompetensi dengan menggunakan Moderated Regression Anlyisis (MRA). MRA merupakan aplikasi khusus regresi linier berganda, dimana dalam persamaan regresinya mengandung unsur interaksi (perkalian dua atau lebih variabel independen). Uji interaksi ini digunakan untuk mengetahui sejauh mana interaksi variable struktur audit dan supervisi audit dapat mempengaruhi kompetensi pada kinerja auditor. Model persamaan MRA yang digunakan sebagai berikut:

$$
Y=\alpha+\beta_{1} \cdot M_{1}+\beta_{2} \cdot M_{2}+\beta_{3} \cdot X_{1}+\beta_{4}\left(X_{1} \cdot M_{1}\right)+\beta_{5}\left(X_{1} \cdot M_{2}\right)+\varepsilon
$$

Keterangan:

$$
\begin{array}{ll}
\mathrm{Y} & =\text { Kinerja Auditor } \\
\mathrm{a} & =\text { Konstanta } \\
\beta_{1}-\beta_{5} & =\text { Koefisien regresi masing-masing faktor } \\
\mathrm{M}_{1} & =\text { Struktur audit } \\
\mathrm{M}_{2} & =\text { Supervisi audit } \\
\mathrm{X}_{1} & =\text { Kompetensi } \\
\mathrm{X}_{1} \mathrm{M}_{1} & =\text { Interaksi Kompetensi dan struktur audit } \\
\mathrm{X}_{1} \cdot \mathrm{M}_{2} & =\text { Interaksi Kompetensi dan supervisi audit } \\
\varepsilon & =\text { Error }
\end{array}
$$

\section{HASIL PEMBAHASAN}

Variabel kinerja auditor memiliki nilai minimum sebesar 3 dan nilai maksimum sebesar 4 dengan nilai rata-rata sebesar 3,6. Nilai rata-rata sebesar 3,6 menunjukkan bahwa respon responden dalam menjawab pernyataan pada kuesioner cenderung merasa setuju pada masing-masing item pernyataan artinya kinerja auditor cenderung tinggi. Standar deviasi pada variabel kinerja auditor adalah sebesar 1,229. Hal ini menunjukkan bahwa standar penyimpangan data terhadap nilai rata-ratanya adalah 1,229.

Variabel kompetensi memiliki nilai minimum sebesar 2,9 dan nilai maksimum sebesar 4 dengan nilai rata-rata sebesar 3,5. Nilai rata-rata sebesar 3,5 menunjukkan bahwa respon responden dalam menjawab pernyataan pada kuesioner cenderung merasa setuju pada masing-masing item pernyataan artinya kompetensi cenderung tinggi yang berarti responden cenderung mementingkan kompetensi dalam pelaksanaan audit. Standar deviasi pada 
variabel kompetensi adalah sebesar 2,964. Hal ini menunjukkan bahwa standar penyimpangan data terhadap nilai rata-ratanya adalah 2,964.

Variabel struktur audit memiliki nilai minimum sebesar 3 dan nilai maksimum sebesar 4 dengan nilai rata-rata sebesar 3,6. Nilai rata-rata sebesar 3,6 menunjukkan bahwa respon responden dalam menjawab pernyataan pada kuesioner cenderung merasa setuju pada masing-masing item pernyataan artinya struktur audit cenderung tinggi yang berarti responden cenderung mementingkan struktur audit dalam pelaksanaan audit. Standar deviasi pada variabel struktur audit adalah sebesar 2,203. Hal ini menunjukkan bahwa standar penyimpangan data terhadap nilai rata-ratanya adalah 2,203.

Variabel supervisi audit memiliki nilai minimum sebesar 2,7 dan nilai maksimum sebesar 4 dengan nilai rata-rata sebesar 3,7. Nilai rata-rata sebesar 3,7 menunjukkan bahwa respon responden dalam menjawab pernyataan pada kuesioner cenderung merasa setuju pada masing-masing item pernyataan artinya struktur audit cenderung tinggi. Standar deviasi pada variabel struktur audit adalah sebesar 3,169. Hal ini menunjukkan bahwa standar penyimpangan data terhadap nilai rata-ratanya adalah 3,169. Hasil analisis statistik deskriptif pada penelitian ini dapat dilihat pada Tabel 1.

Tabel 1. Hasil Analisis Statistik Deskriptif

\begin{tabular}{llllll}
\hline Variabel & $\mathrm{N}$ & Min. & Max. & Mean & Std. Deviasi \\
\hline Kinerja Auditor $(\mathrm{Y})$ & 44 & 3 & 4 & 3,6 & 1,229 \\
Kompetensi $\left(\mathrm{X}_{1}\right)$ & 44 & 2,9 & 4 & 3,5 & 2,964 \\
Struktur Audit $\left(\mathrm{M}_{1}\right)$ & 44 & 3 & 4 & 3,6 & 2,203 \\
Supervisi Audit $\left(\mathrm{M}_{2}\right)$ & 44 & 2,7 & 4 & 3,7 & 3,169 \\
\hline
\end{tabular}

Sumber: Data Penelitian, 2019

Pengujian data dalam penelitian ini menggunakan teknik analisis regresi moderasi MRA (Moderated Regression Analysis). Perhitungan koefisien regresi moderasi dilakukan dengan analisis regresi melalui software SPSS 20.0 for Windows, diperoleh hasil yang ditunjukkan pada tabel 2 berikut:

Tabel 2. Hasil Uji Analisis Regresi Moderasi (MRA)

\begin{tabular}{|c|c|c|c|c|c|c|}
\hline \multirow[t]{2}{*}{ Model } & & \multicolumn{2}{|c|}{ Unstandardized Coefficients } & Standardized & \multirow[t]{2}{*}{ Sig. } & \multirow{2}{*}{$\begin{array}{ll}\text { Hasil } & \mathrm{U} \\
\text { Hipotesis } & \end{array}$} \\
\hline & & $\bar{B}$ & Std. Error & Beta & & \\
\hline \multirow{4}{*}{1} & (Constant) & 15.241 & 2.636 & & .000 & \\
\hline & $\mathrm{X}_{1}$ & .166 & .080 & .236 & .041 & H1 Ditima \\
\hline & $\mathrm{X}_{1} \cdot \mathrm{M}_{1}$ & .012 & .004 & .793 & .002 & H2 Diterima \\
\hline & $\mathrm{X}_{1} \cdot \mathrm{M}_{2}$ & .005 & .001 & .780 & .000 & H3 Diterima \\
\hline
\end{tabular}

Sumber: Data Penelitian, 2019

Berdasarkan perhitungan analisis regresi moderasi, maka didapatkan hasil persamaan regresi moderasi sebagai berikut:

$$
\hat{Y}=15,241+0,166 X_{1}+0,012 X_{1} \cdot M_{1}+0,005 X_{1} \cdot M_{2}
$$

Nilai konstanta $a=15,241$ memiliki arti apabila kompetensi, struktur audit dan supervisi audit konstan maka nilai kinerja auditor $(Y)$ sebesar 15,241 satuan. Nilai koefisien $\left(\beta_{1}\right)$ sebesar 0,166 . Nilai koefisien positif menunjukkan bahwa apabila kompetensi meningkat sebesar 0,166 dengan asumsi variabel bebas lainnya dianggap konstan. Nilai koefisien $\left(\beta_{2}\right)$ interaksi antara struktur audit dengan kompetensi sebesar 0,012. Nilai koefisien positif hal ini menunjukkan interaksi struktur audit mampu memperkuat kompetensi terhadap kinerja 
auditor pada Kantor Akuntan Publik. Nilai koefisien $\left(\beta_{3}\right)$ interaksi antara supervisi audit dengan kompetensi sebesar 0,012. Nilai koefisien positif hal ini menunjukkan interaksi supervisi audit mampu memperkuat kompetensi terhadap kinerja auditor pada Kantor Akuntan Publik.

Hipotesis pertama $\left(\mathrm{H}_{1}\right)$ tentang kompetensi memiliki pengaruh pada kinerja auditor bahwa semakin tinggi kompetensi dapat meningkatkan kinerja auditor. Berdasarkan tabel 2 nilai $\beta_{1}$ sebesar 0,166 dan nilai signifikansi sebesar 0,041< 0,166, maka hipotesis pertama $\left(\mathrm{H}_{1}\right)$ diterima. Hal ini berarti kompetensi berpengaruh positif dan signifikan pada kinerja auditor. Semakin tinggi kompetensi yang dimiliki oleh auditor maka kinerja auditor akan semakin meningkat karena auditor yang berkompeten biasanya memiliki kemampuan dan kemauan yang cepat untuk mengatasi permasalahan kerja yang dihadapi.

Hasil penelitian ini selaras dengan penelitian yang dilakukan oleh Dyana \& Yadnya (2017) yang menunjukkan bahwa kompetensi berpengaruh signifikan terhadap kinerja auditor. Hal ini juga didukung oleh Sujana (2012), Ariani (2015) dan Nurnaluri \& Cahyaniza (2017) dalam penelitiannya mengungkapkan bahwa kompetensi berpengaruh positif dan signifikan terhadap kinerja auditor. Namun hasil yang berbeda diungkapkan oleh Linawati \& Suhaji (2012) dan Sholihah (2018) menemukan bahwa kompetensi tidak berpengaruh signifikan terhadap kinerja auditor.

Berdasarkan hasil perhitungan dengan menggunakan uji Moderated Regression Analysis (MRA) yang ditunjukkan pada tabel 2, diketahui bahwa nilai $\beta_{2}=0,012$ dengan tingkat nilai signifikansi sebesar 0,002 yang berarti angka tersebut lebih kecil dari nilai taraf nyata yaitu 0,05 . Hal tersebut menunjukkan bahwa variabel struktur audit merupakan variabel moderasi yang memperkuat pengaruh kompetensi pada kinerja auditor. Dengan demikian hipotesis $\left(\mathrm{H}_{2}\right)$ diterima.

Hasil pengujian hipotesis kedua menunjukkan bahwa dengan adanya struktur audit memperkuat kompetensi pada kinerja auditor di Kantor Akuntan Publik. Struktur audit dapat membantu auditor dalam melaksanakan tugasnya menjadi lebih baik sehingga dapat meningkatkan kinerja auditor. Penggunaan struktur audit memiliki keuntungan yaitu: dapat mendorong efektivitas, dapat mendorong efisiensi, dapat mengurangi litigasi yang dihadapi KAP, dan dapat memfasilitasi diferensiasi pelayanan atau kualitas sehingga meningkatkan kinerja auditor. Sebagai auditor yang memiliki keahlian dan pelatihan teknis yang cukup maka sudah dikatakan memiliki kompetensi. Auditor yang memiliki kompetensi akan lebih cepat dan tepat dalam menyelesaikan tugasnya.

Hal ini menunjukkan bahwa bila seorang auditor proses auditnya ditopang dengan stuktur audit yang memadai maka auditor akan mampu menguatkan kompetensi untuk mencapai kinerja audit yang lebih baik dan sebaliknya jika tidak ada struktur audit dalam pengerjaan tugas auditor maka kompetensi yang dimiliki auditor akan menurun dan menghasilkan kinerja auditor yang kurang baik.

Berdasarkan hasil perhitungan dengan menggunakan uji Moderated Regression Analysis (MRA) yang ditunjukkan pada tabel 2, diketahui bahwa nilai $\beta_{3}=0,005$ dengan tingkat nilai signifikansi sebesar 0,000 yang berarti angka tersebut lebih kecil dari nilai taraf nyata yaitu 0,05 . Hal tersebut menunjukkan 
bahwa variabel supervisi audit merupakan variabel moderasi yang memperkuat pengaruh kompetensi pada kinerja auditor. Dengan demikian hipotesis $\left(\mathrm{H}_{3}\right)$ diterima.

Hasil pengujian hipotesis ketiga menunjukkan bahwa dengan adanya supervisi audit memperkuat kompetensi pada kinerja auditor di Kantor Akuntan Publik. Supervisi audit dapat mempengaruhi individu maupun organisasi dalam melaksanakan tugasnya. Supervisi audit dapat memberikan feedback dan supervisor menumbuhkan hubungan yang baik antara atasan dan bawahan akan mendorong auditor menyelesaikan pekerjaan secara optimal. Auditor yang memiliki kompetensi akan bekerja dengan keterampilan dan pengetahuannya sehingga dapat menyelesaikan tugas dengan mudah, cepat, dan dengan pengalaman dibidang yang sesuai dengan pekerjaannya sehingga dapat mengurangi kesalahan.

Hal ini menunjukkan bahwa bila seorang auditor disupervisi oleh supervisor atau manajer akan dapat memotivasi dirinya untuk menguatkan kompetensi guna mencapai kinerja audit maksimal dan sebaliknya jika tidak ada supervisi dalam melakukan audit maka kompetensi auditor akan menurun sehingga menghasilkan kinerja audit yang kurang optimal.

Tabel 3. Hasil Koefisien Determinasi

\begin{tabular}{llllll}
\hline Model & $\mathrm{R}$ & $R$ Square & Adjusted $R$ Square & $\begin{array}{l}\text { Std. Error of the } \\
\text { Estimate }\end{array}$ \\
\hline 1 & $.892^{\mathrm{a}}$ & .796 & .781 & .575
\end{tabular}

a. Predictors: (Constant), X1_M2, X1_M1, X1

Sumber: Data Penelitian, 2019

Besarnya nilai Adjusted R square adalah sebesar 0,781 yang artinya sebesar 78,1 persen variasi kinerja auditor dipengaruhi oleh kompetensi serta struktur audit dan supervisi audit sebagai pemoderasi sedangkan sisanya sebesar 21,9 persen dipengaruhi oleh faktor lain yang tidak dimasukkan ke dalam model penelitian.

\section{Tabel 4. Hasil Uji F}

\begin{tabular}{lllllll}
\hline Model & & Sum of Squares & $\mathrm{df}$ & Mean Square & $\mathrm{F}$ & Sig. \\
\hline \multirow{3}{*}{1} & Regression & 51.766 & 3 & 17.255 & 52.153 & $.000^{\mathrm{b}}$ \\
& Residual & 13.234 & 40 & .331 & & \\
& Total & 65.000 & 43 & & & \\
\hline
\end{tabular}

Sumber: Data Penelitian, 2019

Berdasarkan hasil uji, nilai signifikansi $\mathrm{F}$ adalah sebesar 0,000 yang lebih kecil dari $0,05(\mathrm{~F}<\mathrm{\alpha})$ yang berarti variabel bebas yaitu kompetensi $\left(\mathrm{X}_{1}\right)$, serta struktur audit $\left(X_{2}\right)$ dan supervisi audit $\left(X_{3}\right)$ sebagai pemoderasi berpengaruh signifikan secara simultan atau serempak terhadap variabel terikat yaitu kinerja auditor $(Y)$.

Hasil uji penelitian ini ditemukan bahwa variabel kompetensi berpengaruh positif pada kinerja auditor, struktur audit memperkuat pengaruh kompetensi pada kinerja auditor dan supervisi audit memperkuat pengaruh kompetensi pada kinerja auditor. Penelitian ini didukung oleh teori atribusi karena berfokus pada faktor-faktor yang mempengaruhi kinerja auditor, khususnya pada karakteristik pribadi dan eksternal auditor. Auditor yang memiliki kompetensi yang tinggi disertai dengan struktur audit yang yang baik 
dalam pelaksanaan tugasnya, dan dengan peran supervisor dalam memberikan bimbingan kepada auditor junior dapat meningkatkan kinerja auditor, sehingga menghasilkan kinerja yang baik.

Penelitian ini menghasilkan bahwa pengaruh kompetensi berpengaruh signifikan pada kinerja auditor. Hal ini mendukung pendekatan kontingensi yang menyebutkan mampu mengidentifikasi bentuk-bentuk optimal seperti kompetensi pada kinerja auditor dalam pengendalian organisasi di bawah kondisi operasi yang berbeda dan mencoba untuk menjelaskan bagaimana prosedur operasi pengendalian organisasi tersebut. Hasil uji dalam penelitian ini ditemukan bahwa kedua variabel moderasi yaitu struktur audit dan supervisi audit mampu memoderasi pengaruh kompetensi pada kinerja auditor.

Hasil penelitian ini dapat menjadi pertimbangan bagi auditor dalam meningkatkan kompetensi dengan cara mengikuti pelatihan-pelatihan ilmu statistik berbasis komputer, meningkatkan struktur audit dengan cara mengikuti koordinasi yang di tetapkan KAP tempat auditor bekerja, meningkatkan supervisi audit dengan cara atasan auditor memberikan feedback yang jujur, terbuka, dan interaktif agar kinerja auditor menjadi lebih baik, meingkatkan kinerja auditor dengan berpartisipasi memberikan usulan kepada supervisor mengenai bagaimana harusnya pekerjaan audit dilakukan dan sebagai pertimbangan dalam mengambil kebijakan dalam melaksanakan tugasnya dengan mempertahankan sikap kompetensi yang didukung dengan struktur audit dan tindakan supervisi audit.

\section{SIMPULAN}

Kompetensi berpengaruh positif pada kinerja auditor di Kantor Akuntan Publik. Semakin tinggi kompetensi yang dimiliki auditor maka kinerja auditor akan semakin meningkat dan sebaliknya jika kompetensi yang dimiliki auditor rendah, maka kinerja auditor akan menurun. Struktur audit menguatkan pengaruh positif kompetensi pada kinerja auditor di Kantor Akuntan Publik. Hal ini berarti struktur audit dapat mempengaruhi auditor dalam menambah kompetensi mengenai pemahaman struktur audit yang tepat sehingga membuat kinerja auditor semakin baik. Supervisi audit menguatkan pengaruh positif kompetensi pada kinerja auditor di Kantor Akuntan Publik. Hal ini berarti supervisi audit merupakan tindakan yang dapat mempengaruhi auditor melalui hubungan yang baik antara atasan dan bawahan dalam mengerjakan tugasnya dan menambah kompetensi bagi auditor junior.

Bagi Kantor Akuntan Publik (KAP), guna meningkatkan kompetensi auditor dengan cara memberikan pendidikan pelatihan secara berkala kepada auditor dan meningkatkan fasilitas-fasilitas sehingga mendukung kinerja auditor agar kompetensi auditor meningkat. Bagi auditor, disarankan turut berpartisipasi memberikan usulan kepada supervisor mengenai prosedur audit. Supervisor sebaiknya memberikan feedback yang jujur, terbuka, dan interaktif agar kinerja auditor menjadi lebih baik. Diperlukan komunikasi dan koordinasi yang baik dengan pemimpin dalam proses penyusunan program audit guna pemahaman pendekatan struktur audit ditetapkan dengan baik. Bagi penelitian selanjutnya, penelitian ini diharapkan mampu menjadi refrensi bagi peneliti selanjutnya yang tertarik meneliti mengenai kinerja auditor dan disarankan untuk menambahkan 
jumlah variabel independen, moderasi atau variabel intervening guna mengetahui variabel-variebel lain yang dapat mempengaruhi, memperkuat atau memperlemah variabel independen. Misalnya dengan menggunakan organizational citizenship behavior.

\section{REFERENSI}

Aiman, N. (2017). Pengaruh Struktur Audit, Independensi Auditor dan Profesionalisma Auditor Terhadap Kinerja Auditor Pemerintah (Studi pada Badan Pemeriksa Keuangan Republik Indoneisa Perwakilan Provinsi Jawa Barat ). Skripsi. Fakultas Ekonomi dan Bisnis Unpas 12(1), 145.

Al-khaddash, H., Nawas, R. Al, \& Ramadan, A. (2013). Factors Affecting The Quality Of Auditing: The Case Of Jordanian Commercial Banks. International Journal of Business and Social Science, 4(11), 206-222.

Ariani, K. G., \& Badera, I. D. (2015). Pengaruh Integritas, Obyektivitas, Kerahasiaan, dan Kompetensi Pada Kinerja Auditor Inspektorat Kota Denpasar. E-Jurnal Akuntansi Universitas Udayana, 10(1), 182-198.

Azza S.M Gaballa and Zhou Ning. (2011). An Analytical Study of the Effects of Experience on the Performance of the External Auditor. International Journal Confrence on The Performance of The External Auditor, 1(3), 169-173.

Bamber, E. Michael, Doug Snowball, and R. M. T. (1989). Audit Structure and Its Relation to Role Conflict and Role Ambiguity: An Empirical Investigation. The Accounting Review, 64(2), 285-299.

Bonner, S. E., \& Sprinkle, G. B. (2002). The Effects of Monetary Incentives on Effort and Task Performance: Theories, Evidence, and a Framework for Research. Accounting, Organizations and Society, 27(2002), 303-345. https:/ / doi.org/https:/ / doi.org/10.1016/S0361-3682(01)00052-6

Bowrin, A. R. (1998). Review and Synthesis of Auditing Structure Literature. Journal of Accounting Literature, 17, 40.

Chandara, F. K. (2006). Pengaruh Tindakan Supervisi Terhadap Kinerja Auditor Internal Dengan Motivasi Kerja Sebagai Variabel Intervening (Studi Empiris Pada Pt. Bank Abc). Thesis. Universitas Diponegoro.

Coram,P., Ng, J., \& Woodliff, D. (2003). A Survey of Time Budget Pressure and Reduced Audit Quality Among Australia Auditors. Australian Accounting Review, 13(29), 38-44. https://doi.org/https://doi.org/10.1111/j.18352561.2003.tb00218.x

Dali, N., \& Mas'ud, A. (2014). The Impact of Professionalism, Locus of Control, and Job Satisfaction on Auditors' Performance: Indonesian Evidence. International Journal of Business and Management Invention, 3(10), 63-73.

Dyana Intan Pratiwi, N. M., \& Yadnya, I. P. (2017). Pengaruh Free Cash Flow, Struktur Aset, Risiko Bisnis dan Profitabilitas Terhadap Kebijakan Hutang. E-Jurnal Manajemen, 6(1), 60-86.

Elizabeth, H., \& Friska, F. (2013). Faktor-faktor yang Memengaruhi Kinerja Auditor. Jurnal Bisnis Dan Akuntansi, 15(1), 13-28. https:/ / doi.org/https:/ / doi.org/10.34208/jba.v15i1.205

Eriani, E. (2010). Pengaruh Struktur Audit, Konflik Peran, dan Ketidakjelasan Peran Terhadap Kinerja Auditor(Studi pada KAP di Sumatera Barat). Skripsi. Fakultas Ekonomi Universitas Andalas. 
Erwin Hadisantoso, Sudarma, I.M. \& Rura, Y. (2017). The Influence of Professionalism and Competence of Auditors Towards the Performance of Auditors. Scientific Research Journal Hasanuddin University, V(I), 10-14. www.scirj.org

Fitriani dan Daljono. (2012). Pengaruh Tekanan Ketaatan, Kompleksitas Tugas, Pengetahuan dan Persepsi Etis Terhadap Audit Judgement. Diponegoro Journal Of Accounting, 1(1), 1-12.

Govindarajan, V. (1986). Impact of Participation in the Budgetary Process on Managerial Attitudes and Performance: Universalistic and Contingency Perspectives. A Journal of The Decision Science Institute, 17, 496-516. https:/ / doi.org/https:/ / doi.org/10.1111/j.1540-5915.1986.tb00240.x

Hartanto, Hansiadi Yuli dan Kusuma, I. W. (2001). Analisis Pengaruh Tekanan Ketaatan Terhadap Judgement Auditor. Jurnal Akuntansi Dan Manajemen, 3.

Ikatan Akuntan Indonesia (IAI). (2001). Standar Profesional Akuntan Publik (1st ed.). Salemba Empat.

Indriani, P., \& Darmawan, J. (2014). Pengaruh Tindakan Supervisi, Motivasi dan Kerjasama Terhadap Kinerja Auditor PT. Bank Negara Indonesia Tbk Palembang. In Seminar and Call for Paper Economic Globalization: Trend \& Risk for Development Country.

Kalbers, Lawrence P., \& Fogarty, T. J. (1995). Profesionalism its Consequences: a Study of Internal Auditors. Auditing: A Journal of Practice, 14(1), 64-68.

Laksmi, D. (2010). Pengaruh Supervisi, Profesionalisme, Tingkat Pendidikan, dan Pengalaman Kerja terhadap Kinerja Auditor BPK RI Perwakilan Provinsi Bali. Skripsi. Fakultas Ekonomi Universitas Udayana.

Lee, Tom \& Stone, M. (1995). Competence and Independence: The congenial Twins Of Auditing? Journal of Business Finance and Accounting, 22(8), 11691177. https:// doi.org/https:// doi.org/10.1111/j.1468-5957.1995.tb00899.x

Linawati dan Suhaji. (2012). Pengaruh Motivasi, Kompetensi, Kepemimpinan, dan Lingkungan Kerja Terhadap Kinerja Karyawan ( Studi Pada PT . Herculon Carpet Semarang ). Jurnal Kajian Akuntansi Dan Bisnis, 1(1), 1-14.

Murray, D. (1990). The Performance Effects of Participative Budgeting: An Integration of Intervening and Moderating Variables. Behavior Research In Accounting, 2(PP), 104-121.

Muslim A. Djalil. (2002). Persepsi Auditor Tentang Pengaruh Struktur Audit dan Prinsip Organisasional Terhadap Konflik dan Ambiguitas Peran. Lembaga Penelitian Universitas Syah Kuala, 5, 146-162.

Namora, L. L. (2011). Memahami Dasar-Dasar Konseling Dalam Teori Dan Praktik. Kencana Prenada Media Grup.

Nur, S. W., \& Fitri. (2017). The Influence of Independence and Competence of Auditor on The Performance of Inspectorate Auditors District MAROS. International Journal of Science and Research (IJSR), 6(10), 584-587. https:// doi.org/10.21275/ART20177179

Nurnaluri, S., dan Cahyaniza, C. (2017). Pengaruh Kompetensi Auditor Terhadap Kinerja Auditor (Studi Para Inspektorat Provinsi Sulewasi Tenggara). Jurnal Akuntansi Dan Keuangan, 1(2).

Nurul, A. F. A. (2018). Effect Of Competence and Effort Of Auditors To Auditor Performance To The Use Of Information Technology As Variable Mediation. 
Russian Journal of Agricultural and Socio-Economic Sciences, 6(June), 496-504. https:// doi.org/https:/ / doi.org/10.18551/rjoas.2018-06.26

Pamilih, I. (2014). Pengaruh Independensi, Gaya Kepemimpinan, Komitmen Organisasi dan Pemahaman Good Governance Terhadap Kinerja Auditor Pemeritah (Studi Empiris pada Kantor BPKP Perwakilan Yogyakarta). Jurnal Universitas Muhamadiyah Surakarta, 1-16.

Prabhawa, K. A., Herawati, N. T., \& Putra, I. M. P. A. (2014). Pengaruh Supervisi, Provesionalisme, dan Komunikasi Dalam Tim pada Kinerja Auditor Perwakilan BPKP Provinsi Bali. E-Jurnal Akuntansi Universitas Pendidikan Ganesha Jurusan Akuntansi Program S1, 2(1), 1-10. https:// doi.org/http://dx.doi.org/10.23887/jimat.v2i1.2486

Raiyani, N. L. K. P., \& Suputra, I. D. G. D. (2014). Pengaruh Kompetensi, Kompleksitas Tugas, dan Locus of Control Terhadap Audit Judgment. EJurnal Akuntansi Universitas Udayana, 6(3), 429-438. http://ojs.unud.ac.id/index.php/Akuntansi/article/view/8335\%0Ahttps:/ /www.mysciencework.com/publication/show/b2cafda066f026efeec6c81aa 16331c9

Sandy Alfianto dan Dhini Suryandari. (2015). Pengaruh Profesionalisme, Komitmen Organisasi dan Struktur Audit Terhadap Kinerja Auditor. Accounting Analysis Journal Universitas Negeri Semarang, Indonesia, 4(1), 1-9. https:// doi.org/10.15294/aaj.v4i1.7732

Santoso, A. P. (2012). Pengaruh Kompetensi Auditor dan Time Budget Pressure Terhadap Kualitas Audit (Studi Kasus pada Kantor Akuntan Publik Wilayah Bandung). Skripsi. Universitas Widyatama.

Sholihah, P. (2018). Pengaruh Budaya Organisasi, Independensi, Kompetensi, Gaya Kepemimpinan dan Profesionalisme Terhadap kKinerja Auditor. (Studi Empiris pada Kantor Akuntan Publik di Surakarta dan Yogyakarta). In Skripsi. Universitas Muhammadiyah Surakarta.

Siagian, H. L., \& Karo, H. (2018). the Effect of Auditor Competence, Emotional Intelligence of Auditors, and Auditor Independence on Auditor Performance. Jurnal Terapan Ilmu Manajemen Dan Bisnis (JTIMB) Universitas Advent Indonesia, 1(1), 82-97. https:// doi.org/10.35974/JTIMB.V1I1.710

Sitorus, R. R., \& Wijaya, L. (2016). Pengaruh Profesionalisme dan Etika Profesi Terhadap Kinerja Auditor dengan Struktur Audit Sebagai Pemoderasi. Jurnal Media Studi Ekonomi Universitas 17 Agustus 1945 Jakarta, 19(2), 98-119.

Spencer, L. and S. M. S. (1993). Competence at Works Models for Superior Performance. John Wiley \& Sons, Inc. https:// doi.org/https:/ / doi.org/10.1002/hrdq.3920050411

Suharni. (2017). The Effect Competence, Professional Ethics of Auditors To Work Performance and Emotional. International Conference and Call for Papers, 6, 669-690.

Sujana, E. (2012). Pengaruh Kompetensi, Motivasi, Kesesuaian Peran dan Komitmen Organisasi Terhadap Kinerja Auditor Internal Inspektorat Pemerintah Kabupaten (Studi Pada Kantor Inspektorat Kabupaten Badung dan Buleleng). Jurnal Ilmiah Akuntansi Dan Humanika, 2(1), 1-27. https:// doi.org/10.1017/CBO9781107415324.004

Tethool, R. K., \& Rustiana. (2003). Dampak Interaksi Tindakan Supervisi dan 
Pengalaman Kerja Terhadap Kepuasan Kerja Auditor: Studi Empiris di KAP Yogyakarta, Semarang dan Solo. Journal of Business and Economics Universitas $\begin{array}{llll}\text { Atma Jaya } & \text { Yogyakarta, } & 7(1), & 12-20 .\end{array}$ https:// doi.org/https:/ / doi.org/10.24002/kinerja.v7i1.781

Winidiantari, P., \& Widhiyani, N. (2015). Pengaruh Konflik Peran, Ketidakjelasan Peran, Struktur Audit, Motivasi dan Kepuasan Kerja Pada Kinerja Auditor. E-Jurnal Akuntansi, 12(2), 249-264. 